\title{
Inclusion of Pupils with Autism Spectrum Disorder: Art Education Strategies and Peer Collaboration - A Case Study in Lisbon, Portugal
}

\author{
Marta Gaspar, Tereza Ventura \\ University Fernando Pessoa, Lisbon - Portugal
}

\begin{abstract}
The action-research project [1] that supports the present paper intended to verify if creativity in Fine Arts contributes to scholar inclusion of students with autism spectrum disorders (ASD). The inductive process was based on semi-structured interviews to teachers involved in the educational process of the pupil and to parents, and also on direct participant observation of the action, as privileged means of investigation. The results obtained showed that the use of strategies of the scope of the Visual Arts, the creative / proactive attitude and the partnership between all the teachers, contributed to the development of communication / expression of the pupil, promoting mutual assistance, and increasing his socialization and inclusion. Thus stresses the great importance of sharing of information, experiences and strategies among all those involved in the teaching-learning process of these pupils.
\end{abstract}

\section{Introduction}

The problem that set off this investigation is the relationship between creativity in the Visual Arts and the inclusion of pupils with ASD: how this intervention / experience benefits these pupils, if the arts stimulate their imagination / creativity and promote their inclusion / socialization, that is to say what is the contribution of creativity in the Visual Arts for the "inclusive education", towards an effective implementation of the concept of "inclusive school".

In fact we assumed, as a starting point, what is referred to in Glória "Creative experiences require the development of relationships and the refinement of personal discoveries, creativity is the function of the transactional relationship between the individual and the environment in which he is engaged" [2].

It was believed that the most individuals develop their creative ability the most they are able to be critical, reflective and able to accept the difference and to include it in their experiences, considering it indispensable for the development of the creative process.
It was believed that greater diversity of individuals, working together, regardless of their needs and abilities, guaranties a richer creative process and becomes, for all, an event of more integral personal training. "The most important art of the teacher is to awaken the motivation for creativity and for the knowledge." [3].

The process of inclusion through creativity makes "more abundant the teaching-learning process for all pupils, giving everyone a greater magnitude to create, (...) not just one or the other, but in all artistic areas, globally, in musical, dramatic, danced or verbal expression, in literary expression ... among others" [4].

The art not only facilitates the finding of the "Self" as a social being, it is also an excellent vehicle for knowledge, as it allows greater ease in acquiring knowledge: “(...) education through the arts that follows from the meeting of modern pedagogy with the new artistic experiences, promote the humanistic education of the individuals, by the integration and harmony of experiences and acquisitions, facilitating the scholarship inclusive development, in a physical and mental balance (...)" [5].

Thus, in the view of above referred authors, under a pedagogical perspective, any educational institution should promote the development of the creativity of his pupils, because all pupils are entitled to an education that promotes their scholar and educational success, being essential for this to guaranty the access to artistic education, to facilitate the development of fundamental human capabilities, as the critical spirit, creativity, sensitivity, socialization, inclusion, etc.

Studies about Creativity and Learning, namely in Visual Education [2], [6] shown its contribution to scholar and social development of students, presenting some strategies to promote creative behavior. Although the lack for studies in the area of this action-research project is clear [1], namely those involving pupils with special educational needs (SEN) and with ASD.

Under the objectives assumed for this study and the search for an answer for the departure question, we privileged the pedagogical relationship of peer 
collaboration (between teachers of regular school and special education teacher) to prepare activities interesting different disciplines and contexts. This effort was determinant to promote an inclusive environment that gave maximum support to all pupils involved in this study.

The promotion of peer collaborative work among teachers and the use of strategies and methods proved to be adequate in Plastic Arts, gave support to the implementation of creative activities, under this scope, but were the development and internalization of transversal concepts were possible.

These activities become facilitators of learning, promoting peer help and cooperation, namely between ASD pupil and other colleagues, illuminating his strong abilities, developing his self esteem, promoting his autonomy, facilitating his socialization and inclusion.

\section{Description of the study}

The research work carried out was intended to confirm the contribution of creativity and the arts in the process of socialization and inclusion of a young boy with autism spectrum disorder attending the 2nd cycle of basic education, taking into account that communication and socialization are domains compromised in any subject autistic, albeit in different commitment levels.

Within an action-research project we checked how activities that call for creativity in Visual Arts can be a suitable vehicle for the inclusion of pupils with autism spectrum disorders, bearing in mind that these pupils, culturally, are already integrated into regular schools.

The action-research project was implemented by activity contexts and during some phases, previously planned for ten months: Field Recognition (SeptemberOctober, 2013); Design of Inclusive Projects (November, 2013); Diagnose of Study Case (January, 2014); Intervention (March-June, 2014); Reflective Evaluation (May-June, 2014).

The action-research project was conducted by contexts and had several phases of previously scheduled interventions: within the first context - Structured Teaching Unit (STU) - the Studio of Plastic Expression, Personal and Social Development and the Music Workshop - and within the second context - the classrooms in the disciplines of Education for Technology and Musical Education.

In the Studio of Plastic Expression - oriented and coordinated by the first author of this paper, with the support of two special education teachers - the activity was organized by priorities, exposing and developing the specific content covered by the unit, so creative and playful use of arts enable participation in the atelier of other pupils of the school.

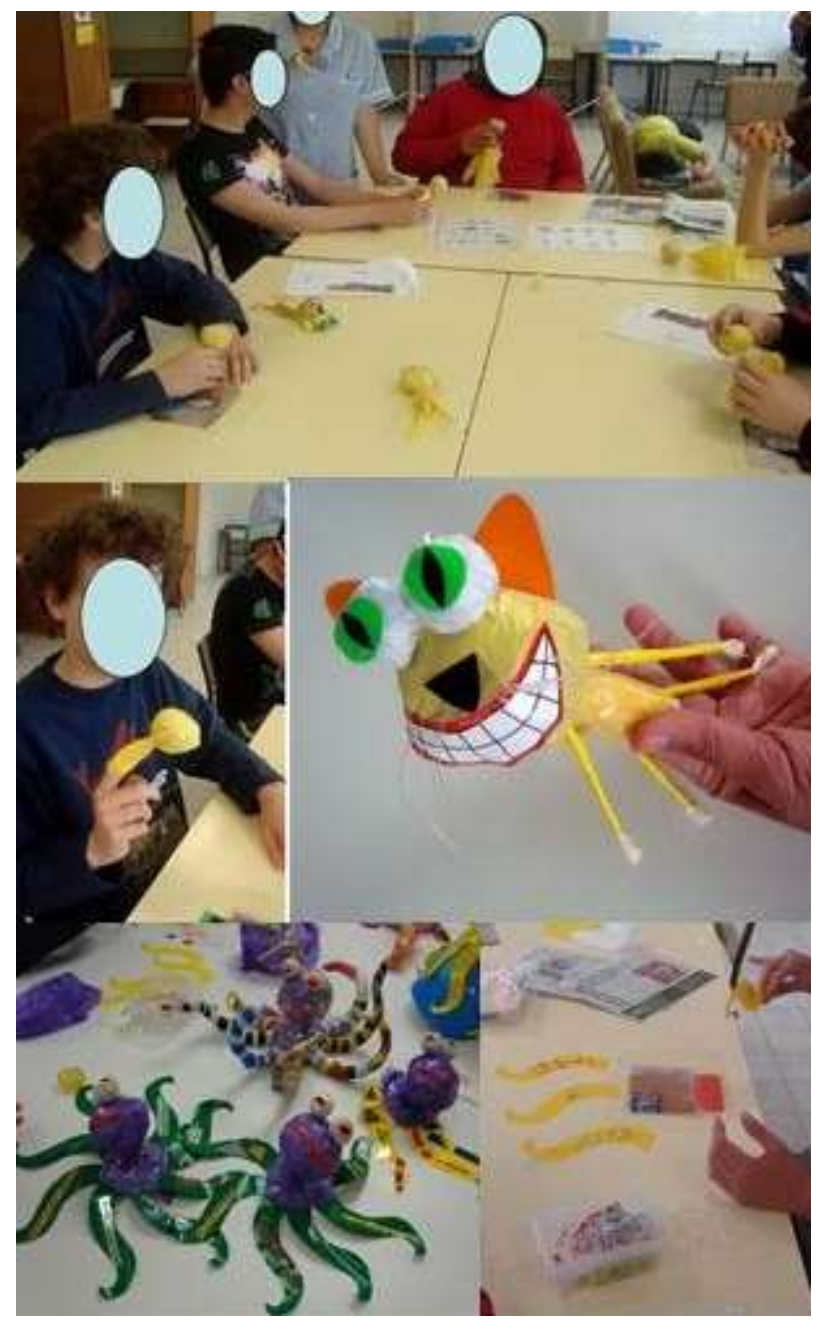

Image 1. Studio of Plastic Expression - Construction of a puppet, a character from a story

We preferred the participation of colleagues integrated in the classes of pupils supported in the STU, having as purpose the sharing of experience and knowledge, looking for the "opening" of the unit itself to the scholar community, so becoming a space integrated in the school and not isolated from it, but allowing inclusion of pupils supported here. In fact and as Correia says "inclusion bring advantages both for pupils with special educational needs and for those that have no such needs" [5].

Regular education pupils who were invited to participate in the activities carried out on STU, as part of this Studio, were assessed by the Director of Class in the discipline of Civics, for his performance in the context of the so-called "Project Sponsors", who sought to promote mutual assistance and exchange of knowledge/experiences between regular education pupils and pupils with autism spectrum disorders of STU. Regular education' pupils enthusiastically participated in this project. 


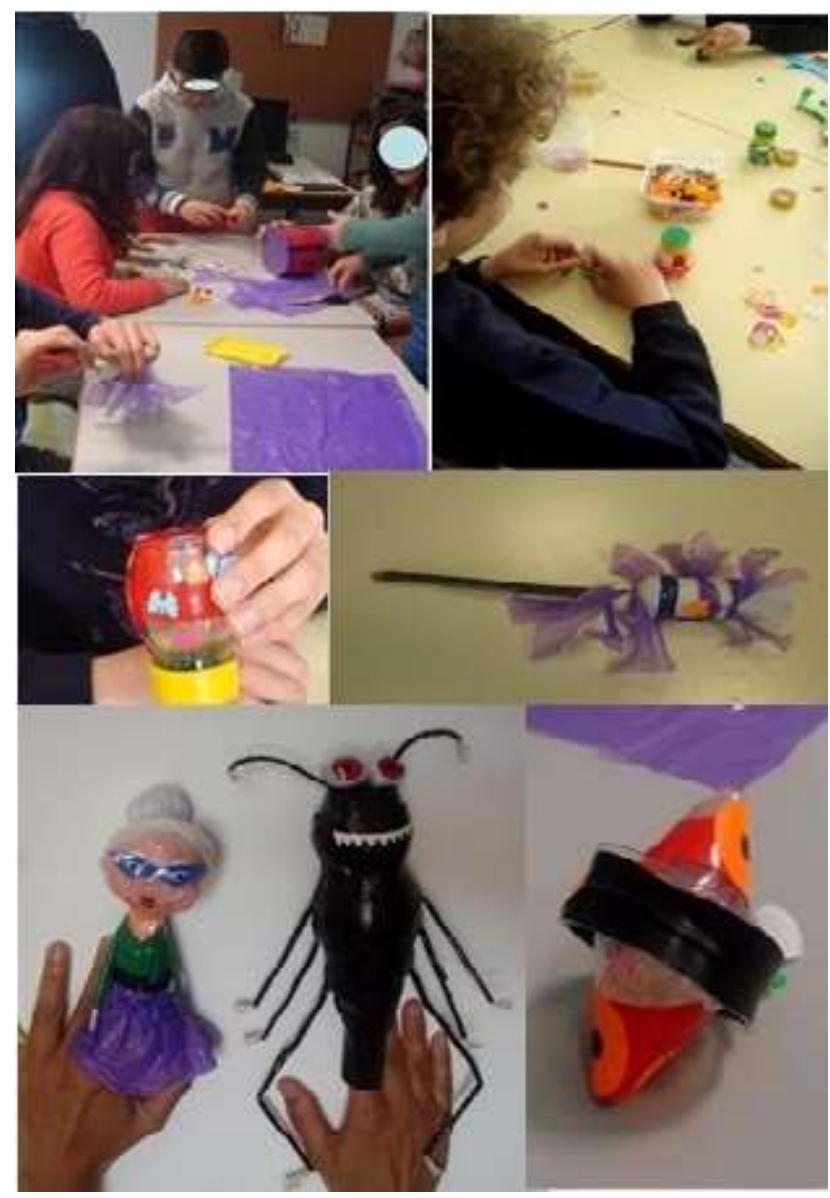

Image 2. Studio of Plastic Expression - "Project Sponsors" - Construction of musical instruments having as theme characters of children's songs: Rain stick and Maraca

During the process of self-regulation of the management of activities, to deepen understanding of the case study, there was also needed to collect some opinions of teachers and parents and these reports were analyzed and synthesized for study's purposes.

During the research-action, on STU, the first author of this article worked with the same commitment with all pupils here supported (six pupils with ASD). The results were very positive with all pupils. The selection of one of the six pupils with ASD for presentation of the results is due only to the extension of a broader study.

\subsection{Methodology and procedures}

The way to implement this research-action project started with the establishment of the departure question: Can creativity in Plastic Arts, in $2^{\text {nd }}$ cycle of Basic Education, be a contribution to inclusion of a pupil with $A S D$ ?
The objectives of this project were defined: to understand how creativity in Plastic Arts, in $2^{\text {nd }}$ cycle of Basic Education, can be a contribution to inclusion of a pupil with ASD, analyzing, in the study case, the adequation of strategies applied in learning of Fine Arts' context; to describe its contribution to the socialization process of a young boy with ASD. As a choice of methodological strategy we decided to apply a qualitative approach as data we needed has to be collected by direct and participant observation of the case - the pupil with ASD in interaction with his colleagues and teachers and the involvement of his family in the projects in course.

The research methods that best fit this study were qualitative in nature, since it was intended to produce a comprehensive study and an interpretation of the educational practice (to explore, describe and analyze, to provide knowledge about the phenomena studied and on the processes applied in action, to see or contrast effects and relationships present in this case). The inductive process was based on semi-structured interviews and direct/participant observation, as privileged means of investigation.

In the course of the action-research, in order to deepen the understanding of the case study, there was needed to collect some opinions of teachers and parents, related to pupils under study. For information gathering various tools were developed: semi-structured interview's guides for teachers and parents and a direct participant's observation grids.

The guide for the interviews to the teachers is composed of 10 questions focused on the followed guidance points: the contribution of creativity to acquire learning, social skills development and inclusion of pupils with ASD; teaching of fine arts as promoter of the socialization of the pupil with ASD and facilitator of the inclusion of the pupil with ASD; teaching of fine arts as a facilitator of a harmonious and safe environment for pupils with ASD; parental involvement in creative/visual arts projects with the pupil with ASD. The guide for the interview with parents consists of 7 questions focused on the orientation points that follow: contribution of creativity to acquire learning, social skills development, and inclusion of the pupil with ASD; teaching of fine arts as promoter of the socialization of the pupil with ASD and facilitator of the inclusion of the pupil with ASD; teaching of fine arts as a facilitator of a harmonious and safe environment to the pupil with ASD; parental involvement in creative/visual arts projects with the pupil with ASD, in school.

With the direct participant observation it was intended to study the relationships, dynamics, ways of doing, strategies, rhythms, the interactions with peers and teachers, in the two above mentioned contexts.

Someone who uses direct participant observation as research method can gather all information that their 
sensorial capacities are able to percept and process significantly. Data needed for this investigation was obtained by means of this type of observation of the pupil in contexts prepared and acting in projects in course.

The observation of this interaction and involvement was organized around topics related to the Visual Arts, in particular, as regards the aspects: stimulating creativity, socialization and inclusion promoter and developer of normalizing contexts. Reports were compiled with detailed descriptions relating the above referred topics (relationships, dynamics, ways of doing, strategies, rhythms, interactions with peers and teachers) in both contexts and in each of the sessions, allowing us to draw conclusions (grounded theory) about how the pupil expressed creativity; how he applied, through creativity, the methods intrinsic to the artistic discipline and develop or acquire intellectual, social and emotional skills, promoting his inclusion; how the pupil socialized, how the pupil was included; how teachers encouraged creativity through teaching Visual Arts using intrinsic methods and strategies to this discipline; how teachers promoted the socialization and inclusion of the pupil.

During the action-research project, in order to a deeper understanding of the study case, we needed to gather some discourses of teachers and parents of pupils with ASD integrated in the STU. The selected segments of teachers' discourse were categorized under four themes: creativity, socialization, inclusion and environments/contexts classroom. The selected segments of parents' discourse were categorized under five themes: creativity, socialization, inclusion and environments/contexts classroom and parental involvement.

The treatment of data categorized validated the findings that were later contrasted with those of other studies presented by other authors.

\subsection{Contextual characterization}

The school where the case took place includes teaching preschool and $1 \mathrm{st}, 2^{\text {nd }}$ and 3rd Cycles of basic education and belongs to a mega Group located in the city center of Lisbon. The school has 80 pupils in pre-school; 160 pupils in the first cycle; 380 pupils in second cycle; 300 pupils in middle school; 1 structured teaching unit (STU) with 6 pupils included in 2nd cycle and 1 support multihandicap unit (SMU) with 6 pupils included in classes of 2 nd cycle. The school has 68 teachers distributed by several degrees of education: 2 educators, 6 teachers of the 1 st cycle, 18 teachers of the 2 nd cycle, 20 teachers of middle school and 12 special education teachers. It also has 2 speech therapists, 1 physiotherapist, 1 social education, technician, 1 rehabilitation technician, 2 psychologists, 2 technical assistants and 16 operating assistants.
Data collecting was based on selection, organization, categorizing, treatment and analysis of contents of the teachers and parents discourses (related with pupils involved in STU), of the contents of semi-structured interviews to teachers involved in learning process of the pupil with ASD, under study, and of registries of direct participant observation for all the projects in course.

The results of data analysis were used to adjust the action in course, to reach objectives assumed, and to facilitate the understanding of the changing process.

\subsection{Characterization of target population}

The pupil observed is a boy of 12 years, with ASD, who lives with his parents and a 16 years old brother without disabilities.

While growing, his parents noticed that his son was different: his eyes were not alive, his orality was poor, he do not interact with his brother, he rejected many aliments, he rotates the lids of pots, incessantly in the kitchen floor, among other unusual behaviors.

When he attempt three years of age his parents consulted the pediatrician. After the gathering and analysis of all information about his development and behavior a diagnose of ASD was established.

The communication / socialization is his compromised domain. $\mathrm{He}$ is accompanied at school, by a speech therapist, a rehabilitation therapist and a psychologist. At home with the family, he speaks correctly but in school, with teachers and classmates, he don't verbalize, articulating the words without sound, and uses examples through the action, or PSC (pictographic symbols for communication). He reads and writes words with great difficulty. Their strengths are mathematics and crafts. He features a very reasonable fine motricity and excellent penmanship. $\mathrm{He}$ is well organized and rigorous. Apparently calm, sometimes he has seizures where he expresses enough violence, both at home and at school.

He attends the 2nd cycle of basic education (CEB), integrated in a structured educational unit (STU), and integrates a group of 5th grade level in three disciplines technologic education, music education and physical education. Technologic education's teacher is effective teacher of the Group of schools, and member of the coordination board of the school, despite finishing the complete specialization in special education during the year on which this study took place (2013/2014). In the previous academic year (2012/2013) he opposed his vote to the opening of Structured Teaching and Support for Multihandicap Units (STU/SMU) at school, not agreeing with the inclusion of their users as pupils in school. Teachers of Music Education and Physical Education are teachers hired. 


\section{Presentation and reflective analysis of the results}

The present work had two main objectives: to understand how creativity in the Visual Arts can contribute to the inclusion of a child with ASD at school and review the appropriateness of strategies / methods used in the artistic education and verify if they contribute to the development and socialization of the child.

According to the results of interviews conducted with teachers, there was established the strong conviction that the fine arts stimulate imagination and creativity, using strategies that are intrinsic to teaching-learning methods of the discipline, developing communication and expression, increasing the autonomy and promoting socialization .

The parents of the pupil under study consider that through creativity in the teaching of fine arts and intrinsic methodologies in this area, learning can be facilitated, exposing the contents in a more interesting and playful way, a view shared with both teachers and parents of other pupils with ASD based on STU, that added to this list also the development of social skills.

According to the teachers the skills to be developed through the applied methodologies and creativity in the teaching of fine arts are not only social but also emotional skills and intellectual ones.

The parents of the pupil, and parents of pupils with ASD based on STU, in this aspect, refer to social and intellectual skills.

The teachers considered that creativity in the arts contributes to the inclusion of the pupil with ASD by providing socialization, through sharing and mutual aid, encouraging tolerance, favoring a peaceful environment, providing equal opportunities and developing self-esteem.

The parents of the pupil in study takes care that creativity arises as a facilitator of inclusion, of communication and socialization. Parents of pupils with ASD based on STU affirm the same opinion saying that creativity in the arts facilitates the inclusion of the pupils with ASD.

Through the activities observed in both contexts above mentioned (direct / participant observation) and taking into account the results obtained with the analysis of the answers to the interviews and reports of speech of the teachers accompanying pupils on study and parents, it was found that they consider of great importance for the success, socialization and inclusion of the pupil with ASD, the way how to meet his needs in the classroom.

In fact, they affirm the importance of the empathy between teacher and pupil, the adoption of a proactive attitude in the classroom by the teacher, the adequate planning of activities for the group/class, with the exchange of experiences / partnership between teachers (regular education and special education) using intrinsic strategies to the disciplines of arts appropriate for each pupil, appreciating the strengths of ALL, generating an environment of respect, mutual and equal opportunities.

It was also affirmed that the use of strategies of the scope of the Visual Arts and creative / proactive attitude of partnership between all the teachers, contributed to the development of communication and pupils expression, promoting mutual assistance, thus contributing to their socialization and inclusion. It was noted the great importance of sharing of information, experiences and strategies among all those involved in the teachinglearning process of the pupil (teachers and parents).

It was verified, through the reports of speech, from teachers and parents of pupils with ASD, based on what they consider a lack of stimulation of the pupil with ASD in the classroom, that thus leads to detachment and indiscipline, hindering their socialization and inclusion. It was noted the need for creativity, developing, in this context, and stimulating dynamic and playful activities, using language connected to practice, facilitating learning, taking into account the whole group but safeguarding the individual characteristics of each one. Through positive interactions and interactive learning the pupils could study in establishing and facilitating their socialization and inclusion. Teachers accompanying pupils on study and guardian consider that the activities developed in the framework of creativity in the Visual Arts, promoted mutual assistance, were facilitators and promoters of communication and expression of the pupils with ASD by providing their socialization and inclusion.

It was found, through direct observation of the pupil with ASD that he participated very well in activities in the field of plastic arts, demonstrating creativity in the way he communicates and expresses himself, how he resolve troubleshoots, choose and apply materials, shows motivated participation in the activities and learning, cooperates with colleagues (helps and is helped) and with the teachers. It was observed that the use of strategies in the context of the arts, promoting mutual aid and the positive interaction between the pupil and their peers and teachers, motivated him, increasing his self-esteem and developing his autonomy throughout this process, having facilitated his socialization and inclusion.

Observing all the activities developed in the two contexts referred above, the pupil with ASD shown to be motivated to participate and cooperate with his peers and teachers, and he developed his competencies (social, emotional and intellectual ones). The boy feels more confident, autonomous and happy, and these facts contributed to facilitate his socialization and inclusion.

His colleagues in the classroom showed always a great interest on the proposed activities, were very well integrated in the team and glad to be able to aid the pupil with ASD, so there is no one registry of rejection. This pupil was always considered an element of the team, as all 
other peers, exchanging experiences and learning. His inclusion in the team was total.

It is consensual that it is essential to articulate the school with family, these being the main institutions "responsible" for the socialization of the child and the provision of a quality education for all. Due to the specificities of the SEN pupils with ASD it is of great relevance to their scholar success the cooperation between teachers and parents.

We conclude that the questioning about the origin of the problems, in order to prepare an educative effective environment, determined by action-reflection, was very important.

The special education teacher assumed the main role in the promotion of collaborative work between teachers, to improve the changing needed in the learning process. His role was also important promoting interdisciplinarity and transdisciplinarity, bringing other teachers to the perception of the value of creative results that occurred during interactive processes between different knowledge areas.

\section{Discussion of the results}

It turns out that there are several authors who attest a positive relationship between creative activities / motivation to learning / socialization and inclusion, revealing that a more creative and proactive teaching relationship is of great importance to the success, socialization and inclusion in the school [2], [7], [8], [9], [10], [11], [12], [13], [14], [15].

It was noted during the present study that the arts stimulate imagination and creativity using strategies and creative methods intrinsic to the discipline, develop communication and expression, increasing the autonomy and promoting socialization of the pupil with ASD.

This is in accordance with Stern and Cramond: "Creative education makes the child more secure, more self-confident, stronger, more resistant to adverse situations, better prepared to overcome the obstacles that society presents to him daily.

Being creative is to be balanced, the opposite of an aggressive or desperate individual" [14]. "In fact, to educate in creativity, points to creative motivation both of the pupil and the teacher, that has to assume also a creative attitude" [16].

It was also found that through the creativity in the teaching of fine arts and applying intrinsic methodologies in this area, we can propose a facilitated learning, exposing the contents in a more interesting and playful manner, promoting the development of social, emotional and intellectual skills of the pupil with ASD.

Also, as says Brás: "Artistic activities are forms of development and expression of motricity, of intelligence, of sociability and child creativity. Activities of artistic creation help the child with educational needs or not, to discover himself, in his action and realization, that is to say, in the self affirmation, to the rising of his creativity, by the idea proposed ( ...) or by the techniques and materials used, that is to say to become autonomous and responsible, to grow for life in group (...) and to awake his aesthetic sense" [8].

It was noted that the activities developed in the framework of creativity in the Visual Arts contributed to the inclusion of the pupil with ASD by providing socialization, through sharing and mutual aid, encouraging tolerance, favoring a peaceful environment, providing equal opportunities and developing the self-esteem of the pupil with ASD, highlighting their strengths. These results are in line with those of Correia that argues that "mutual help were confidence and mutual respect are essential characteristics, that leads to gather strategies (...) so important to strengthen the strong areas of students and to the formulation of answers adequate to their needs" [9].

It was also found in this study that the use of strategies of the scope of the Visual Arts and creative / proactive attitudes, of partnership between all the teachers, contributed to the development of communication and expression of the pupil under study, promoting mutual assistance, thus contributing to his socialization and inclusion, results in line with Correia: “(...) to plan learning and participation to all the pupils without resorting to stereotypical and predetermined answers, to search for better forms of adapting curricula modifications to the diversity of needs of the students, to work in cooperation with other professionals and services, to promote collaboration and exchange of information and experience between teachers, to encourage production of materials, mutual observation of classes, the emergence of pedagogical partnership, to increase experimentation and pedagogical innovation, are some of main tasks were teachers has to be actively involved, whatever are their functions." [10].

It was noted the great importance of sharing of information, experiences and strategies among all those involved in the teaching-learning process of the pupil, and between teachers and family.

It was found that the lack of stimulation of the pupil with ASD in the classroom leads to detachment and fosters the indiscipline hindering their socialization and inclusion.

These conclusions are in line with Vayer, Carvalho and Tilstone: "What children think about someone that is different $(. .$.$) is determinant for the integration or non-$ integration of this one in the children's world." [11]. "The teacher's role is at the level of development skills of autistic child. He promotes the individual balance, the most harmonious, fostering the emotional well being, approaching them of the world, encouraging interpersonal 
relationship significant, having in mind that educational models are needed to able the child to acquire competences, namely those compromised as of social interaction and communication, language and attention" [17]. "In fact, cooperative work among peers promotes exchange of ideas and promotes personal success of pupils, enhancing self-esteem and diversity acceptance" [12].

It was noted the need for creativity, namely to develop and to stimulate activities, playful and dynamic, using language linked to the practice, facilitating learning, having regard to the whole group but safeguarding the individual characteristics of each one.

As referred by Lindquist "The child better expresses herself by means of non-verbal language, unlike adults that are better able to express verbally their needs. Frequently children are not able to express themselves clearly although, through art and games they expresses their feelings, realize their wishes, promoting their affective and cognitive development and helping them to know and dominate their own body and to maintain social relationship" [13].

It was noted, from the data collected on direct observation, that after the intervention the pupil improved: communication and expression; motricity; learning; autonomy; self-esteem; socialization and inclusion.

Correia believes that the inclusion allows students with special needs to acquire academic and communication skills to prepare them for life in the community. Inclusion "provides similar learning and appropriate social interactions (...) in a spirit of belonging and participation in all aspects of school life" [9].

\section{Conclusions}

The present case study sought to contribute to a deeper understanding of the concept of "inclusive school" and processes that can facilitate its implementation. With it, we intended to check and confirm if creativity in the Visual Arts can be a suitable vehicle for the inclusion of pupils with autism spectrum disorder, taking into account that these pupils, culturally, are already integrated into regular schools.

The process of implementation and development of an inclusive education in mainstream schools has been complex and therefore has taken place very slowly and full of restrictions. "Several authors argue that the inclusion has to do with the restructuring of schools, said "regular" in the sense of these go to meet the needs and abilities of their students, so that everyone can in regular context, access to the quality in education" [18] Thus, it is essential that schools bet in teacher training, encouraging teachers to a collaborative training, cooperative and critical, so that they can, in schools, help all students, whether they are or not people with special needs.

In addition to the school restructuring it is also necessary openness to change by the teachers, which should be available for questioning, rethinking and redesign methodologies, techniques and practices. It is urgent that teachers reflect together on their practices, "learn" to share their classrooms, their fears, doubts, methods, strategies, activities, because only through experimentation and joint reflection it is possible to reach alternative and creative forms to face tasks and problems leading to the deepening of professional practice.

Groups with different levels of capabilities that provide differentiated inclusive education make sense for both teachers and pupils. However, for some teachers, provide differentiated instruction requires a paradigm shift. "When teachers practice a differentiated teaching, no longer see themselves as guardians and administrators of knowledge, going to see themselves more as organizers of opportunities to learn. Although the contents remain important, these teachers do not care much to know all the answers, before "reading their students." They try to develop educational situations that capture students' attention and provide understanding of content. To organize a classroom with a view to effective activities and discoveries becomes the top priority " [19].

Inclusive education requires the teacher to realize that classrooms should be privileged places for teaching and learning and that no practice is good unless they work individually.

Before considering specific ways to modify content, processes and products for students with different levels of ability, it is very important to realize the various guidelines that enable inclusive education.

Because all education process must be special, the path during the construction of this project was the rethinking of education for ALL, the rethink teaching and learning in a more creative, attractive, exciting and inclusive view.

With the limitations and the advantages inherent to a case study, this project - that does not allow for generalizations of the results but contributed to a better understanding of the processes - was, for the authors, an enhanced awareness of the great responsibility of teaching, of being a docent, integrating a system that so many times prevents its members to grow, denying school and citizenship of all and for all.

The inclusive school allowed the pupils with ASD to interact with their peers and teachers, developing social, emotional and intellectual skills, facilitated the overcoming of the barriers inherent in their own learning.

It is believed that the sooner we get walking towards the effective scholar inclusion, the deeper and most positive changes will arrive both in the development of individuals with ASD and their social inclusion. 
"The inclusion of all pupils teaches each one, that all people are equally valuable members of society and that it is worthwhile to include them all" [20].

\section{References}

[1] M. Gaspar, "Criatividade nas Artes Plásticas no $2^{\circ}$ ciclo do Ensino Básico como contributo para a inclusão de alunos com perturbações do espectro do autismo"- Estudo de Caso em Lisboa, Universidade Fernando Pessoa, Porto, 2015 .

[2] , M. A. Glória, Criatividade na aprendizagem. Escola Superior de Educação de Paula Frassinetti, Porto, 2012.

[3] A. Estanqueiro, Boas práticas na educação - o papel dos professores. Editorial Presença. Lisboa, 2010.

[4] A. B. Sousa, Educação pela Arte e Artes na Educação. Instituto Piaget. ( $3^{\text {a ed. }) ~ H o r i z o n t e s ~ P e d a g o ́ g i c o s . ~ L i s b o a, ~} 2003$.

[5] A. Santos, Mediações Artístico- Pedagógicas. Livros Horizonte. Lisboa, 1989.

[6] L. B. R. Vale, Como desenvolver a criatividade do aluno em artes visuais. Universidade de Lisboa. Lisboa, 2010 .

[7]S.J. Rogers and B. F. Pennington, A theoretical approach to the déficits in infantile autism. Development and Psychopathology, 3, 57 - 64, 1991.

[8] M. Brás, Actividades na Educação Pré-Escolar e Activação do Desenvolvimento Psicológico. Escola Superior de Educação João de Deus. Lisboa, 1994.

[9] L. M. Correia, Inclusão e Necessidades Educativas Especiais. Um Guia para Educadores e Professores. Colecção Necessidades Educativas Especiais. Porto Editora, Porto, 2005.

[10] L.M. Correia, A Escola Contemporânea e a Inclusão de alunos com NEE. Considerações para uma educação com sucesso. Colecção Impacto Educacional. Secretaria Regional de Educação e Cultura. Porto Editora. Porto, 2008.

[11] P. Vayer, C. Rocin, Integração da criança deficiente na classe. Instituto Piaget. Lisboa, 1992.

[12] C. Tilstone, L. Florian, L.\& R. Rose, Promoting inclusive practice. London, Routledge. London, 2003.
[13] I. Lindquist, In: A Criança no Hospital: terapia pelo brinquedo. p. 103-104. Pagina Aberta. São Paulo, 1993.

[14] A. Stern, Initiation à l'education créatrice. Delachau el Niestlé. Neuchatel, 1970.

[15] M. Rouse and L.Florian, Effective inclusive schools: a study in two countries. Journal of Education 26(1), 7185.Cambridge, 1996.

[16] B. Cramond, Ph.D. Fostering Creativity. Series Editors. 2005

[17] P. Carvalho, Refletir a Integração. Instituto Piaget. Viseu, 2003.

[18] M. Ainscow, Necessidades Educativas Especiais na Sala de Aula. Um Guia para a Formação de Professores. Instituto de Inovação e Educação: Edições UNESCO, 1996.

[19] C. A. Tomlinson, Diferenciação Pedagógica e Diversidade. Colecção Educação Especial. Porto Editora. Porto, 2008.

[20] I. M. Ferreira, Uma Criança com Perturbação do Espectro do Autismo. Escola Superior de Educação. Castelo Branco, 2011. 